Clinical guidance on pharmacotherapy for the treatment of attention-deficit hyperactivity disorder (ADHD) for people with intellectual disability

Miller, J

http://hdl.handle.net/10026.1/17174

10.1080/14656566.2020.1790524

Expert Opinion on Pharmacotherapy

Informa UK Limited

All content in PEARL is protected by copyright law. Author manuscripts are made available in accordance with publisher policies. Please cite only the published version using the details provided on the item record or document. In the absence of an open licence (e.g. Creative Commons), permissions for further reuse of content should be sought from the publisher or author. 
See discussions, stats, and author profiles for this publication at: https://www.researchgate.net/publication/343111713

\section{Clinical guidance on pharmacotherapy for the treatment of Attention-Deficit Hyperactivity Disorder (ADHD) for people with Intellectual disability Expert Opinion On Pharmacotherapy}

Article in Expert Opinion on Pharmacotherapy · July 2020

DOI: 10.1080/14656566.2020.1790524

CITATION

1

3 authors:

Jonjo Miller

National Health Service

9 PUBLICATIONS 157 CITATIONS

SEE PROFILE

Rohit Shankar

University of Plymouth

191 PUBLICATIONS 944 CITATIONS

SEE PROFILE
READS

31

Bhathika Perera

Barnet, Enfield and Haringey Mental Health NHS Trust 29 PUBLICATIONS 147 CITATIONS

SEE PROFILE

Some of the authors of this publication are also working on these related projects:

Project Mental health services for people with intellectual disability in the United Kingdom View project

Project Patient education View project 


\section{Clinical guidance on pharmacotherapy for the treatment of attention-deficit hyperactivity disorder (ADHD) for people with intellectual disability}

Jonjo Miller, Bhathika Perera \& Rohit Shankar

To cite this article: Jonjo Miller , Bhathika Perera \& Rohit Shankar (2020): Clinical guidance on pharmacotherapy for the treatment of attention-deficit hyperactivity disorder (ADHD) for people with intellectual disability, Expert Opinion on Pharmacotherapy

To link to this article: https://doi.org/10.1080/14656566.2020.1790524

\section{曲 Published online: 21 Jul 2020.}

Submit your article to this journal $₫$

Q View related articles $₫$

View Crossmark data \lceil 


\title{
Clinical guidance on pharmacotherapy for the treatment of attention-deficit hyperactivity disorder (ADHD) for people with intellectual disability
}

\author{
Jonjo Millera, Bhathika Perera ${ }^{\mathrm{a}}$ and Rohit Shankar $\mathbb{1}^{\mathrm{b}, \mathrm{c}}$
}

${ }^{a}$ Haringey Learning Disability Partnership, Barnet, Enfield and Haringey Mental Health NHS Trust, London, UK; ${ }^{b}$ Cornwall Partnership NHS Foundation Trust, Threemilestone Industrial Estate Truro, Truro, England, UK; ' Exeter Medical School, Knowledge Spa, Royal Cornwall Hospital Truro Cornwall, Truro, England, UK

\section{ABSTRACT}

Introduction: $A D H D$ causes significant distress and functional impairment in multiple domains of daily life. Therefore, diagnosis and treatment are important to improve the quality of life of people. The pharmacotherapy for ADHD is well established but needs systematic evaluation in Intellectual Disability (ID) populations.

Areas covered: This paper reviews the ADHD pharmacological treatment in people with ID using the PRISMA guidance for scoping reviews to help identify the nature and strength of evidence.

Expert opinion: In the last 20 years, seven randomized controlled trials have evaluated pharmacotherapies for ADHD in people with ID; five looking at methylphenidate. Generally, studies were underpowered; all but two had less than 25 participants. Of the two larger trials one was single blinded and therefore open to bias. Only two used a parallel-group method, the remainder were mostly short crossover trials; not ideal when measuring behavioral and psychological parameters which are long standing. The remaining evidence is made up of observational studies. Methylphenidate and atomoxetine, particularly at higher doses, have shown clear benefits in people with ID. Most people with ID tolerated ADHD medications well. Benefits were seen in behavioral and/or cognitive domains. The evidence base is limited, though promising, for dexamfetamine, clonidine, and guanfacine.
ARTICLE HISTORY

Received 4 April 2020

Accepted 29 June 2020

\section{KEYWORDS}

Attention-deficit hyperactive disorder; hyperkinetic disorder; pharmacotherapy; intellectual disability; learning disability; neurodevelopment

\section{Introduction}

Attention-Deficit Hyperactivity Disorder (ADHD) is a neurodevelopmental disorder with an increased prevalence of $6-16 \%[1,2]$ in people with intellectual disabilities (ID) compared to people without ID where it is estimated as 1.8-8.4\% [3,4].

The Diagnostic and Statistical Manual of Mental Disorders (DSM-5) defines ID as a neurodevelopmental disorder that begins in childhood characterized by intellectual difficulties as well as difficulties in conceptual, social, and practical areas of living [5]. Around $1 \%$ of the population is estimated to have ID [6]. There is a high prevalence of psychiatric, neuropsychiatric, and neurodevelopmental disorders in people with ID [7-10].

Attention-deficit hyperactivity disorder (ADHD) is another of the neurodevelopmental disorders that begins during childhood, manifested with symptoms of inattention and/or hyperactivity \& impulsivity causing a functional impairment [5]. Diagnosis of ADHD is important as a lack of treatment can lead to a poorer quality of life. Studies have shown that ADHD can increase substance misuse, criminal behavior, foster poor academic achievements, increased convictions, de-stabilize relationships, increase the likelihood of unemployment [1114]. One of the main functional impairments is reported to be challenging behavior; for example, verbal and physical aggression. [15].
Management of ADHD includes the use of pharmacological and non-pharmacological treatment options [16]. Pharmacological options are mainly divided into stimulant and non-stimulant medications. Methylphenidate and dexamfetamine preparations are the main stimulant medications licensed to treat ADHD [16]. There are three nonstimulant medications used to treat ADHD; atomoxetine, clonidine, and guanfacine. All five medications have a well-established evidence base in the general population $[17,18]$. Diagnosis and treatment of ADHD in people with ID can be challenging for various reasons. In addition to communication challenges, increased psychiatric and neuropsychiatric comorbidity can make the treatment decisions more challenging.

Missed diagnosis and lack of treatment in people with ID have shown to increase the use of other psychotropic medications such as antipsychotics [8]. Therefore, treatment of ADHD in people with ID is important in order to improve quality of life, reduce functional impairment, and prevent overuse of psychotropic medications. The dearth of suitable studies further limits the treatment of people with ID and ADHD. In this review, we look at the availability and quality of evidence in the pharmacological management of ADHD in people with ID. 


\section{Article highlights}

- The available evidence supports the use of methylphenidate and atomoxetine for ADHD management in people with intellectual disability.

- There is evidence to support the use of higher doses of methylphenidate to treat $A D H D$ in people with intellectual disability.

- There is some evidence for dexamfetamine, clonidine, and guanfacine.

- There is evidence suggesting that people with intellectual disability may respond differently to ADHD medications compared to the general population.

- Further research evaluating the evidence for first- and second-line ADHD medications in people with intellectual disability is warranted.

\section{Method}

\subsection{Search strategy}

A literature review based on PRISMA scoping guidelines was undertaken [19]. PubMed, Medline/EMBASE, and Psychinfo were used to identify all forms of current evidence on ADHD medications in people with ADHD and ID in peer-reviewed journals between 1 January 2000 and 31 January 2020. Keywords used in this search are provided in Appendix A1. The study selection and screening process of identified studies were completed by $J M$, full text articles were then reviewed independently by JM and BP. This is illustrated in pathway 1 .

At the first level, titles were reviewed and excluded due to irrelevance to the search criteria, or studies conducted in animals, or in-vitro. At the second stage of the shortlisting process the abstracts were reviewed and papers excluded for the following reasons: no abstract, not in English language, animal studies, in-vitro studies, poster abstracts, articles published prior to the year 2000 and articles which did not look at ADHD medication in people with ID. Full articles were then obtained for all studies accepted post the first and second review levels and full articles were screened for inclusion in the final analysis.

\section{Results}

A total of 20 studies were found between 1 January 2000 and 31 January 2020. Studies varied from meta-analysis to observational studies. Tables 1-3 provide the result summaries. The sample size for randomized controlled trials varied from ten to 122. All studies but one featured children/young people with ID and ADHD, with an age range of three to 18. One study [20] was done solely in adults $(n=10)$. Methylphenidate was the most researched drug; covered by 10 papers including two systematic reviews.

\subsection{Measures}

ADHD diagnosis in the participants of included studies was mainly made by using DSM-4 criteria. Some studies did not explain how the diagnosis was made. The diagnosis of ID was made using IQ in most studies. Several different scales were used in the studies, which are described in Box 1. The most commonly used scales were 'the Aberrant Behavior Checklist $(A B C)^{\prime}$ [21], 'the ADHD Rating Scale' (ADHD-RS-IV) [22],

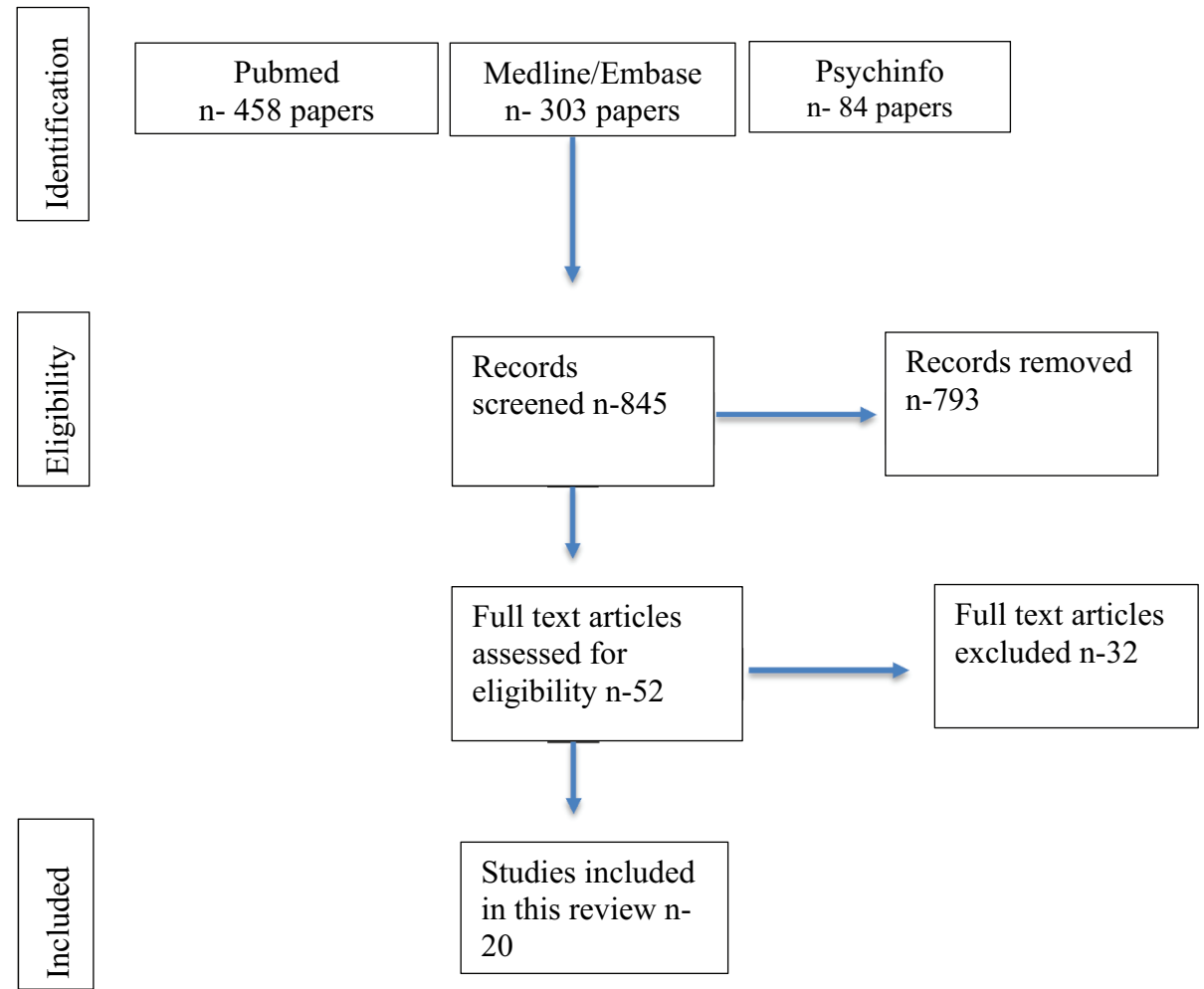

Pathway 1: Selection and screening pathway 
Box 1. ADHD scales used by studies reviewed.

ABC score: Kilincaslan 2016 [58], Simonoff 2013 [35], Aman 2003 [46], Pearson
2003 [42], Capone 2016 [63], Handen 2008 [64].
ADHD-RS-IV: Fernandez-Jaen 2010[55], Kilincaslan 2016 [58], Fernandez-Jaen
2013 [56].
CGI: Fernandez-Jaen 2010[55], Kilincaslan 2016 [58], Fernandez-Jaen 2013
[56], Jou 2005 [57], Mazzone 2011[59], Simonoff 2013 [35], Fosi 2013 [49],
Handen 2008 [64], Posey 2004 [62], Agarwal 2001 [61].
Conners': Fernandez-Jaen 2010[55], Fernandez-Jaen 2013 [56], Jou 2005 [57],
Simonoff 2013 [35], Aman 2003 [46], Pearson 2003 [42].
ACTeRS; Pearson 2003 [42].
SNAP-IV: Filho 2005 [48].
NCBRF: Filho 2005 [48].
RBPC: Aman 2003 [46], Pearson 2003 [42].
CASQ: Aman 2003 [46].
CATQ: Gothelf 2003 [52].
CCPT: Gothelf 2003 [52].

Conners' Parent and Conners' Teacher Rating scales' [22-24], and the Swanson, Nolan, and Pelham SNAP Rating Scale [25]. Box 2 provides a brief explanation of each of the common scales, i.e. parameters they measure and their validity.

\subsection{Evidence for the use of methylphenidate in ADHD in ID}

The literature on methylphenidate in ADHD in people with ID is mainly summarized by two major systematic reviews published in 2018 [33] and 2019 [34], covering the relevant randomized controlled trials within the literature. We discuss these two papers first below, followed by other articles found by our search.

Box 2. Scale scoring systems explained.

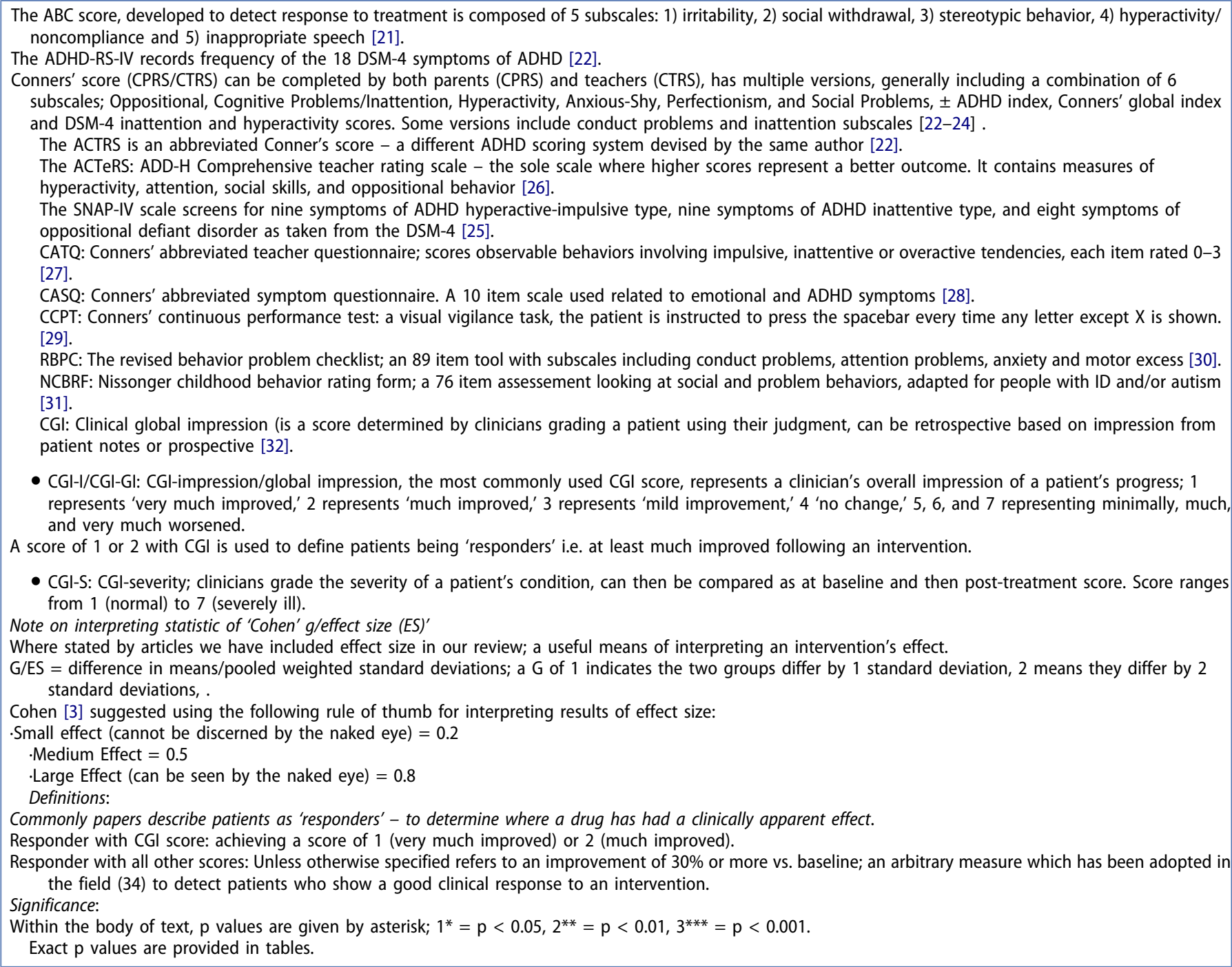




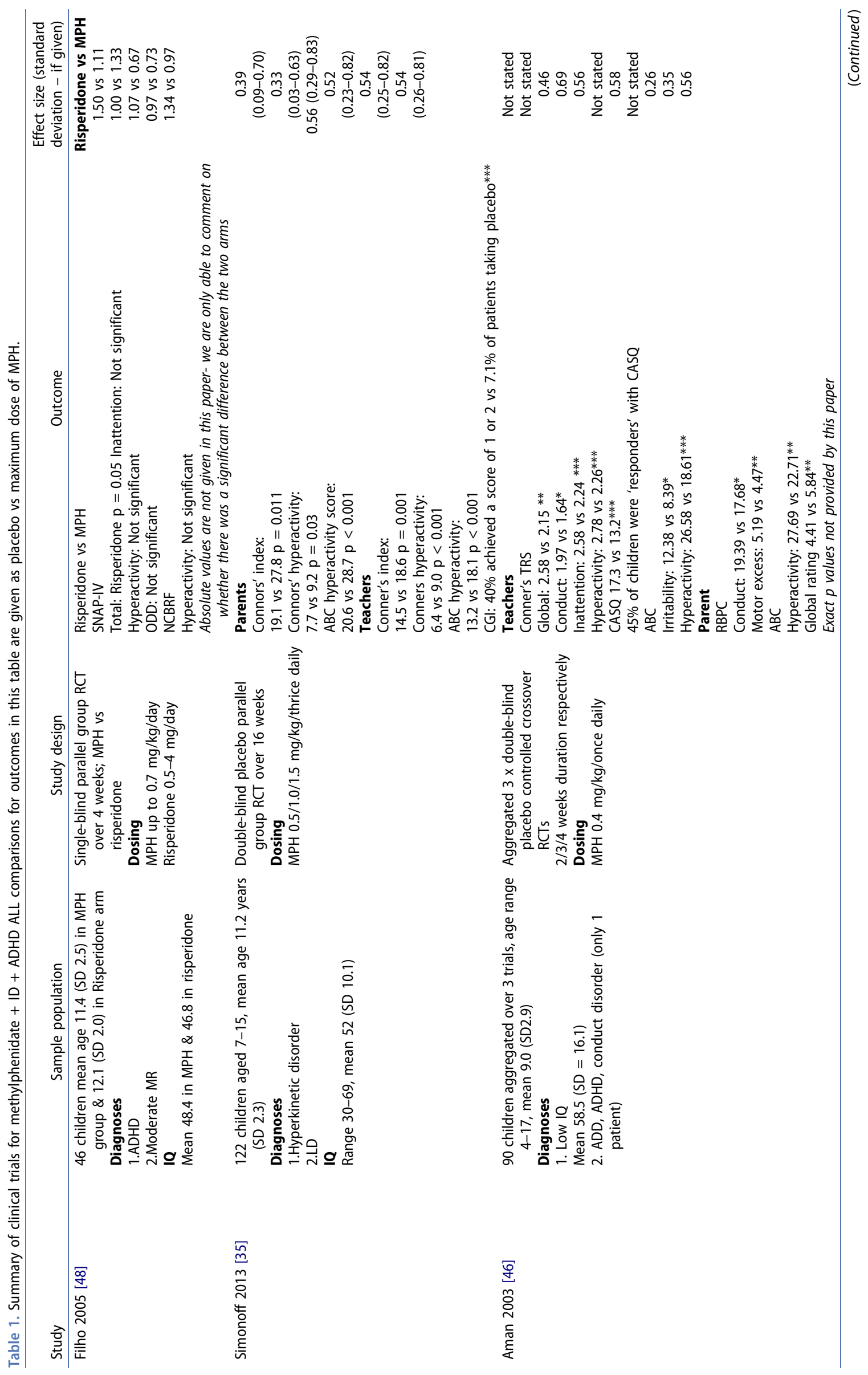




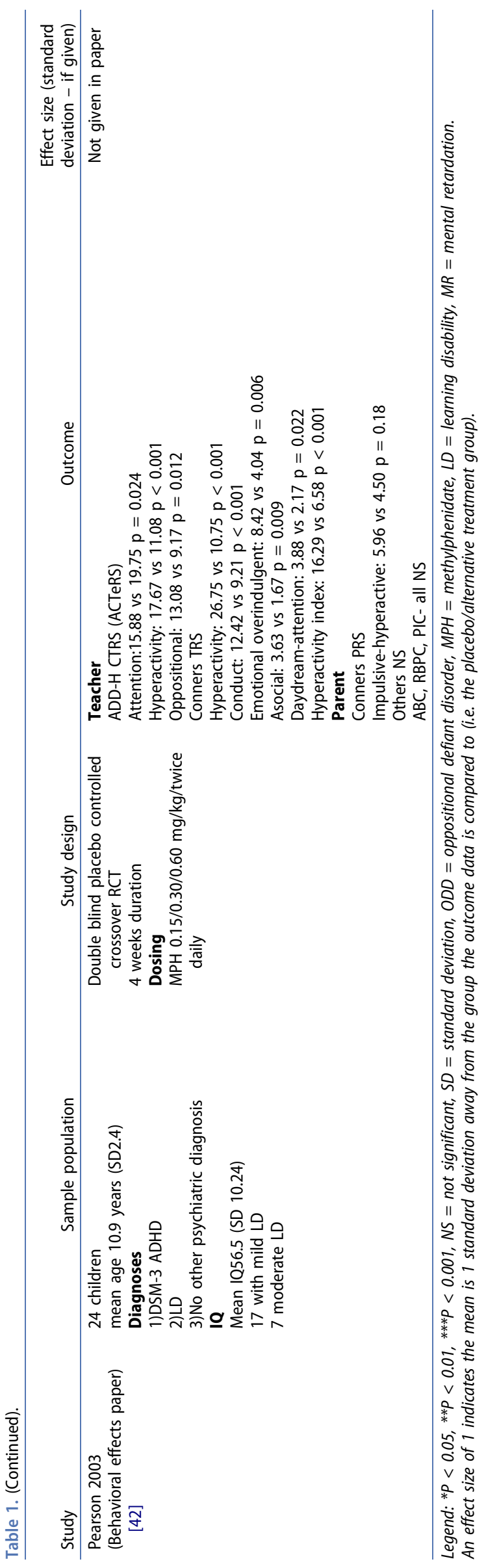

Sun and colleagues [34] reviewed eight studies looking at a total sample size of 242 patients, with mean age 9.17, on methylphenidate and 181 on placebo over a period from 1982 to 2013; all but one [35] were published before the year 2000. IQ range for patients was $30-85$, hence covering people with both ID and borderline intellectual functioning. The primary outcome was an improvement in overall severity of ADHD symptoms. The authors found a significant improvement in ADHD symptoms with MPH vs placebo; effect size (Hedges' $g=0.87895 \%$ Cl 0.612-1.143 $p=<0.001$ ) - highly significant, and $g$ of 0.878 representing a 'large' effect size [36]. Meta-regression analysis suggested a significant positive association between ADHD severity and methylphenidate dosage (slope $=1.335, p<0.001)$ and did not detect a significant association between IQ $(p=0.119)$.

Subgroup-analysis showed that 'high-dose' ( $>0.6 \mathrm{mg} /$ day) patients had a significantly greater improvement in CTRS score (Hedges' $g=1.638$; a very large effect size) vs 'low-dose' ( $<0.6 \mathrm{mg} /$ day) patients (hedges' $G=0.694) p=0.001$ [37]. There were also significant improvements in inattention, hyperactivity, and conduct. There were no significant differences in dropout rates or treatment discontinuation rates between methylphenidate and placebo. This is grade one A evidence that MPH is effective in children with ID and ADHD, in a dose-dependent manner. As the authors state, the data is very heterogeneous, and they do not comment on the prevalence of co-morbidities such as autism which could somewhat influence application to the general population of patients with ID.

A systematic review by Tarrant and colleagues [33] included 13 studies spanning from 1982 to 2013. It included a total of 630 patients aged 4-26 split equally, 315 in each of the placebo and MPH arms, with IQ ranging from unmeasurable to 90. They included all but one [38] of the papers covered by Sun, but also discussed further 7 trials [39-45] omitted from Sun et al. This review reported an average response rate to $\mathrm{MPH}$ of $40-50 \%$, at doses ranging between 0.3 and $1.5 \mathrm{mg} / \mathrm{kg} /$ day. Five were over 8 weeks ( 2 of these 12 or more) while the remainder lasted 3-5 weeks. Due to the heterogeneity of the outcome parameters within their search results, the Tarrant paper was unable to conduct a metaanalysis. They conclude that due to poor quality evidence, 'MPH may be effective in some but not all children and adolescents with ID and ADHD'.

Our search found an aggregate analysis [46] by Aman et al., which itself was not included in Tarrant or Sun papers, though two of its three constituent RCTs were part of Sun's metaanalysis. This looked at three double-blind crossover RCTs investigating the effect of $0.40 \mathrm{mg} / \mathrm{kg} /$ day methylphenidate in 90 children with low IQ aged 4-17 with either ADHD, ADD, or (in one case only) conduct disorder. Mean IQ was 58.5 $(S D=16.1)$. They found a significant reduction in mean teacher's Conners' inattention $\left(13 \%^{* * *}\right)$, hyperactivity $\left(19 \%^{* * *}\right)$, and global scores $\left(17 \%^{* *}\right)$, and CASQ as rated by teachers $\left(24 \%^{* * *}\right)$. Forty-five percent of children were 'responders' (responder in non-CGl scores defined as improvement in score of $30 \%$ or more, unless otherwise specified) in CASQ score. In the $A B C$ hyperactivity score, they found an 
improvement of $30 \%^{* * *}$ as rated by teachers and $18 \% * *$ by parents. Parent 'Global rating' $\left(32 \%^{* *}\right)$, RBPC motor excess $\left(14 \%^{* *}\right)$, and conduct problems $\left(9 \%^{*}\right)$ also showed significant improvements compared to placebo. On subgroup analysis of people with IQ above or below 50 , only $19.4 \%$ of children below 50 were considered to be responders compared to $30 \%$ over 50 .

In another double-blind placebo-controlled crossover RCT of 24 children with ADHD and ID Pearson et al. found significant improvements in both ACTRS and CTRS scores with increasing doses of $\mathrm{MPH}$ up to $0.60 \mathrm{mg} / \mathrm{kg} /$ day [42]. With teacher-rated scores there were significant improvements in ACTRS attention $\left(20 \%^{*}\right)$, hyperactivity $\left(37 \%^{* * *}\right)$, and oppositional behavior $(30 \% *)$. With Conners' TRS significant improvements of $60 \%^{* * *}$ in hyperactivity, $44 \%^{*}$ in daydream attention, and $60 \%^{* * *}$ in hyperactivity index were reported. Furthermore, looking into the relationship between dose and efficacy the authors found that $\mathrm{MPH}$ had a significant curvilinear doserelated relationship in patients with ID and ADHD in cognitive functions, sustained attention, visual/auditory selective attention, and inhibition/impulsivity suggesting the linearity of the relationship even on a low dose can produce a small improvement compared to placebo [41]. In addition to ADHD symptoms, there were also improvements of $57 \%^{* *}$ in social behaviors, $26 \%^{* * *}$ in conduct problems, and 52\%** in emotional overindulgence scores. MPH was well tolerated, showed greater efficacy in hyperactivity than inattention.

In a separate publication analyzing the same data set, Pearson and colleagues [47] found that a proportion of these patients when experienced an initial mild cognitive (35\%) or behavioral (38\%) decline vs placebo in the first week of low dose $0.15 / \mathrm{mg} / \mathrm{kg} \mathrm{MPH}$. In the fourth week on maximum dose of MPH $(0.60 \mathrm{mg} / \mathrm{kg})$, this fell to $9 \%$ of patients showing some cognitive or behavioral decline. The authors postulate this represents normal fluctuations in the population; i.e. at any time patient's condition may worsen; though this was less likely to occur when they were on high dose MPH. They also found that improvements in behavioral or cognitive function occurred independently; i.e. the absence of a behavioral response does not mean the patient has failed to exhibit a cognitive benefit and vice versa.

Simonoff et al.'s major double-blind placebo-controlled randomized controlled trial of 122 children with the hyperkinetic disorder and ID found strong evidence that MPH in an optimaltitrated dose of $0.5,1.0$, or $1.5 \mathrm{mg} / \mathrm{kg} /$ thrice daily was superior to placebo [35]. In the primary outcomes of parent and teacher's Conners' index; MPH showed significant benefit with effect sizes of $0.39 \mathrm{p}=0.011(95 \% \mathrm{Cl} 0.09$ to 0.70$)$ and 0.52 $\mathrm{p}=0.001$ (95\% Cl 0.23 to 0.82 ) respectively, and no correlation between IQ or presence of autistic symptoms. On CGI score, $40 \%$ of patients were judged improved or very much improved with $\mathrm{MPH}$ vs $7 \%$ of the placebo arm. This paper was included in the previously described systematic reviews; however, we describe it further separately here due to it being the largest trial to date in this group by a factor of around three.

Filho and colleagues [48] in a single-blind parallel group 4week RCT compared risperidone $0.5-4 \mathrm{mg} /$ day vs. MPH up to
$0.7 \mathrm{mg} / \mathrm{kg} /$ day in 45 children with ADHD and moderate LD. They found a significantly greater improvement $(P=0.05)$ clinically with risperidone compared to $\mathrm{MPH}$, though the improvement was also seen in the MPH arm. However, there was a significant $(p<0.05$ ) weight gain of $1.01 \mathrm{~kg}$ in the risperidone group, vs. weight loss of $0.53 \mathrm{~kg}$ in the MPH group. Handen and colleague's open-label prospective observational study investigating the impact of ADHD on tests of play skills in children with ID showed that MPH significantly improved scores of directly observed play intensity and global ratings of activity; two areas where the children with ADHD had a deficit at baseline [44].

There have been smaller studies looking at prescribing $\mathrm{MPH}$ in people with ADHD and ID and other conditions. Epilepsy is known to be more prevalent in patients with both $A D H D$ and ID. Fosi et al. looked at $\mathrm{MPH}$ in patients with ID, ADHD, and severe epilepsy examined in a retrospective open-label observational study in 18 patients with treatment-refractory epilepsy, $67 \%$ of whom had severe LD [49]. Sixty-one percent were rated as improved on treatment with $\mathrm{MPH}$ in CGI-I scores. ADHD is commonly associated with certain genetic syndromes such as William's syndrome. Green et al.'s retrospective observational study [50] described the response of 18 children with a mean age 6.3 (SD 1.4) with William's syndrome and ADHD, treated with $\mathrm{MPH}$ mean dose of $10.5 \mathrm{mg} /$ day (SD5.9), for a mean duration of 4.3 years (SD 3.8). Of all participants, $72.2 \%$ of patients were considered as treatment responder according to CGI-I scores [50].

Velocardiofacial syndrome (VCFS) can be associated with ID. No papers looking at solely people with ID and VCFS were identified. However, Green [51] published a trial in 34 patients with VCFS given $\mathrm{MPH}$, which found a clinically significant improvement in $72 \%$ of patients, in whom the mean IQ was 82.8 (SD10.5). Gothelf [52] found in a 4 week prospective open-label observation study, in children with VCFS, low dose $(0.3 \mathrm{mg} / \mathrm{kg} / \mathrm{od}) \mathrm{MPH}$ was effective in improving ADHD symptoms. The 12 patients treated came from an initial group of 18, in whom the mean IQ was 77.0 SD \pm 15 ; however, for the treated patients, no exact IQ is stated. Mean CATQ score decreased by $49 \%$ after treatment; this was highly significant with $p<0.0001$. Neuropsychological testing in the form of CCPT found significant improvements $1 \mathrm{~h}$ after MPH administration in omission errors, variability of reaction time, and 'hits' (all $\mathrm{P}<0.05$ ). There was a strong negative correlation between MPH improvement in CCPT index and IQ ( $r=-0.68, p=0.01)$; useful negative evidence that the lower IQ group with VCFS responded sub-maximally.

\subsection{Evidence for the use of dexamphetamine in ADHD in ID}

Dexamphetamine works by increasing synaptic extracellular dopamine and norepinephrine levels in the prefrontal cortex [53]. Though dexamphetamine are first-line ADHD medications [16], the evidence base in the ID population has been limited. The sole result was a Cochrane review of amphetamine in ADHD in ID published in 2009 [54]. Within this, the only paper meeting inclusion criteria was a double-blind $\mathrm{RCT}$ of 
amphetamine vs MPH vs placebo [38], in 15 children (mean age 7.9) with fragile $x$-syndrome and mean $\mathrm{IQ}$ of 58 . Dexamphetamine $0.2 \mathrm{mg} / \mathrm{kg}$ given once daily was found to cause no significant improvement vs placebo in ADHD symptoms as assessed by Conners' parents/teachers questionnaire and ACTRS.

\subsection{Evidence for the use of atomoxetine in ADHD in ID}

Atomoxetine is a commonly used non-stimulant ADHD medication. It is recommended as a second-line treatment by NICE Guidelines [16]. Despite this, studies have shown that atomoxetine is a commonly prescribed ADHD medication in people with ID and ADHD [10]. Our search produced five papers on the use of atomoxetine in treating ADHD in people with ID (Table 2). All studies were conducted in children with ID and included a total of 185 children with mild to severe ID.

Fernandez-Jaen and colleagues [55] in their open-label prospective observational study investigated the effect of atomoxetine mean dose $1.22 \mathrm{mg} / \mathrm{kg} /$ day over a period of 16 weeks, in 48 children ages 5-19, with ID and ADHD. There was a statistically significant improvement of $22 \%^{* * *}$ in CGI-S, and in ADHD-RS-IV scores; $31 \%^{* * *}$ as measured by parents, and $33 \%^{* * *}$ as measured by teachers $\left(^{*}=p<0.05\right.$, $\left.{ }^{* *}=p<0.01,{ }^{* * *}=p<0.001\right)$. This indicates atomoxetine was effective in reducing the severity of ADHD (CGI-S) as assessed by clinicians, and ADHD symptoms as assessed by parents and teachers (ADHD-RS-IV). Forty-nine percent of patients were 'responders' with CGI-I; indicating clinicians judged patients to be either 'much' or 'very much' improved (a score of 1 or 2). Conners' score concurred, with significant improvements in both inattention and hyperactivity subscales, and an improvement of $27 \%^{* * *}$ and $34 \%^{* * *}$ in total score with parent and teachers, respectively. This study found no correlation between age or level of ID for any outcome. On follow up, 23 patients continued on treatment at 1 year, with patients discontinuing due to perceived inefficacy/intolerance or cost of treatment.

Fernandez-Jaen and colleagues in a second study [56] conducted a prospective open-label observational study for 24 children with ADHD and pervasive developmental disorders (PDD) for 16 weeks. Nineteen (80\%) of the children in this study had ID. Atomoxetine dose ranged from 25 to $60 \mathrm{mg}$, once daily. There was a statistically significant improvement in all Conners' subscales of attention, hyperactivity/impulsivity, and conduct problems; with an improvement of $28 \%^{* *}$ in total score, \& in ADHD-RS-IV subscales of inattention \& hyperactivity; with an improvement of $23 \%{ }^{* * *}$ in the total score as rated by parents. Similarly, with scores assessed by teachers, a significant improvement in all subscales was demonstrated; total ADHD-RS-IV score improved by $27 \% * *$ and Conners' $21 \% *$, this was not influenced by the presence of ID. Five patients discontinued due to inefficacy or intolerability, out of the remaining 19 , fifteen patients were still on treatment at 1 year - no reason is stipulated for further drop-outs.

Jou and colleagues [57] reported a retrospective open-label observational study of atomoxetine in 20 children between 6

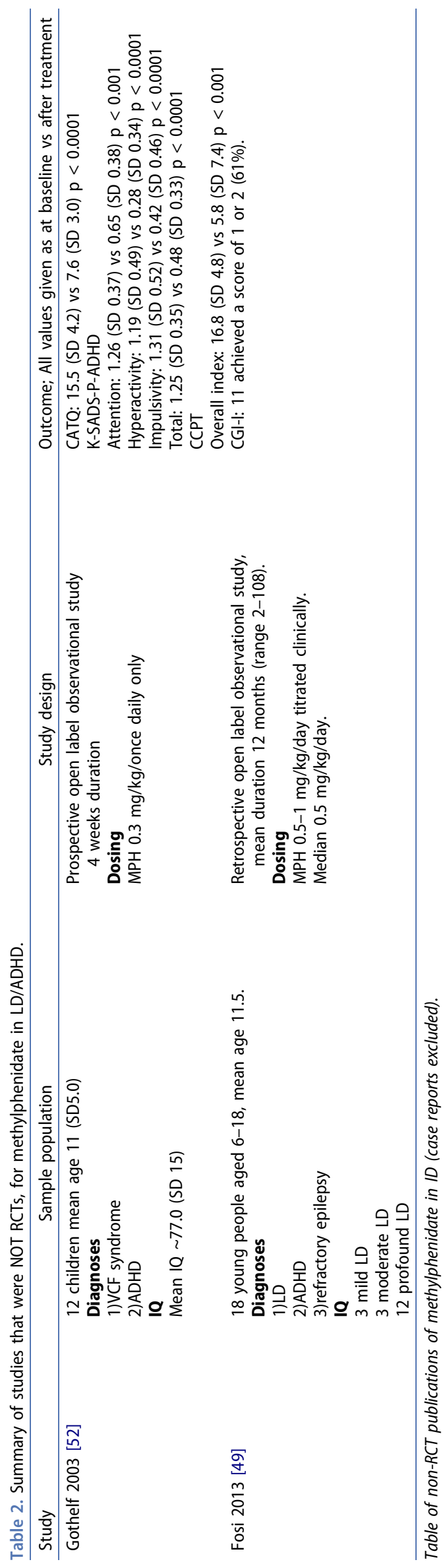




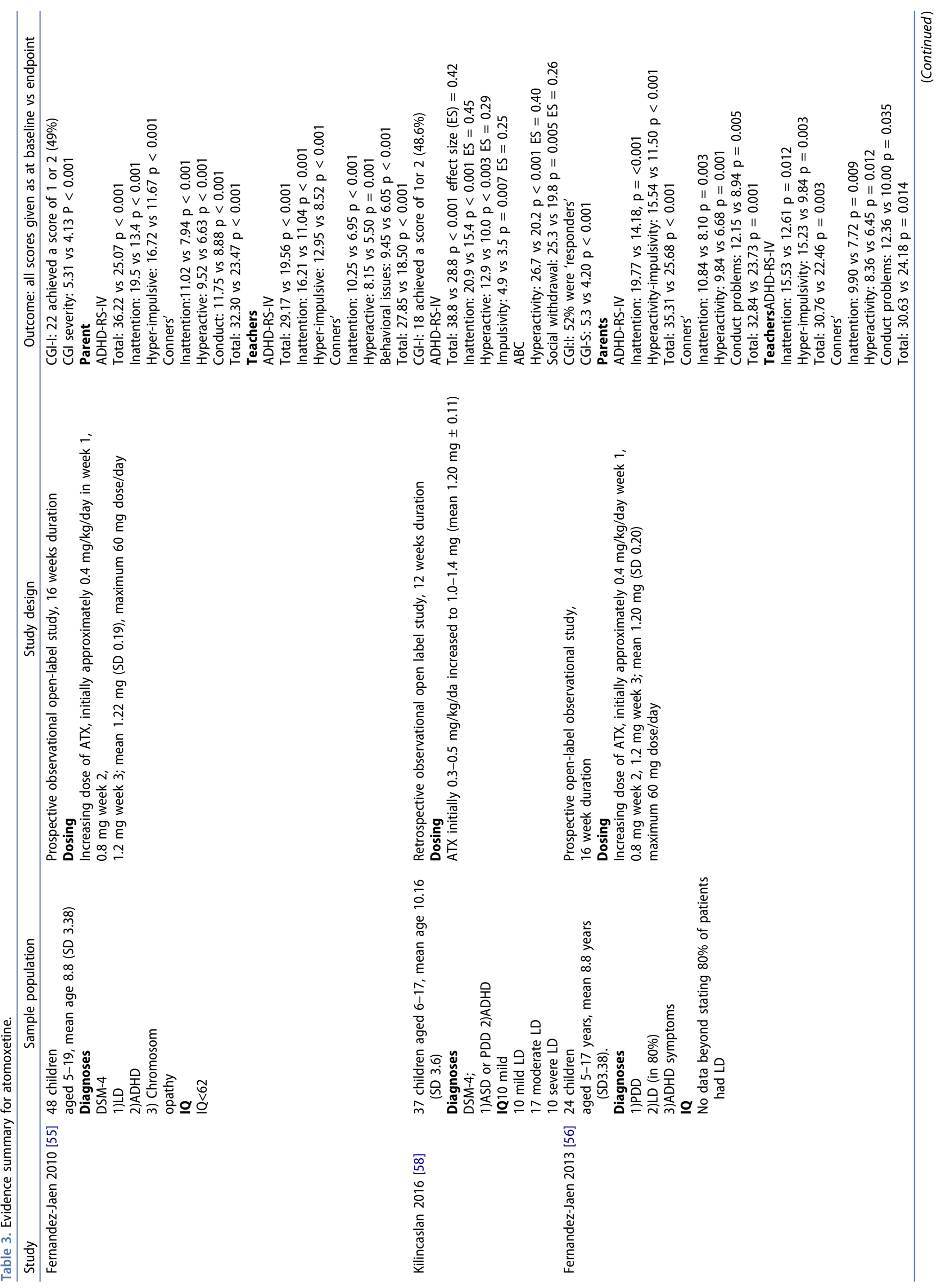




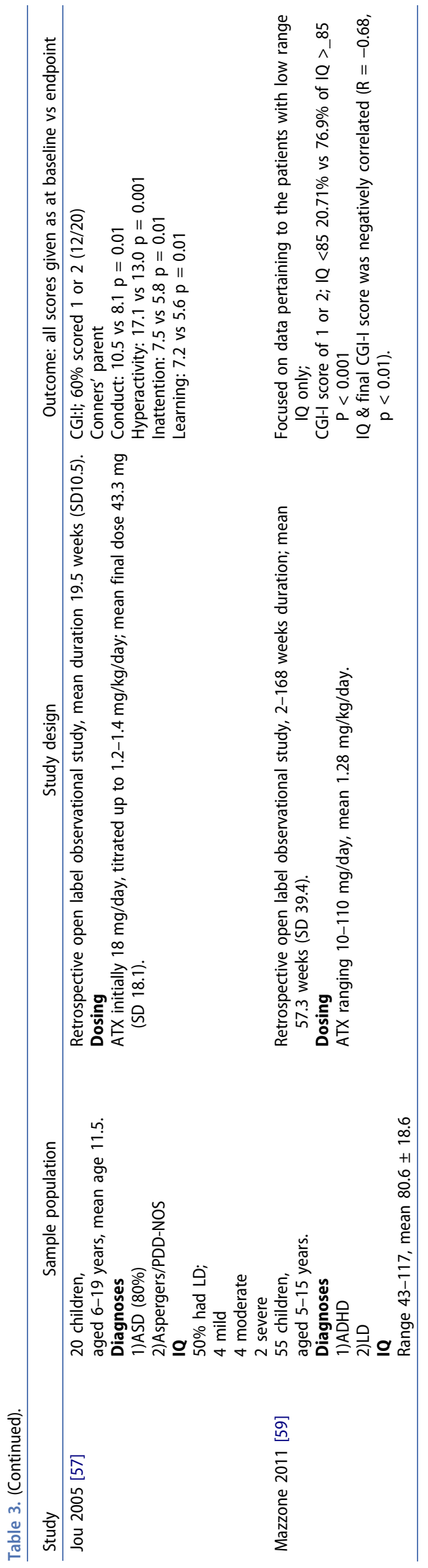

and 19 years of age (mean 11.5 years). This study assessed the benefit of a mean dose of atomoxetine $43.3 \mathrm{mg}$ (standard deviation (SD) 18.1) for a mean duration of 19.5 weeks (SD 10.5) on ADHD symptoms in patients with PDD, 10 of whom had diagnosed ID, using CGI-GI (clinical global impression global improvement score), 16 had comorbid autism. The initial dose was $18 \mathrm{mg} /$ day, titrated up to $1.2-1.4 \mathrm{mg} / \mathrm{kg} / \mathrm{day}$. Twelve patients were deemed 'responders' on CGI-Gl; of whom six (50\%) had ID; two mild, two moderate, and two severe. Of the eight non-responders, four patients (50\%) had ID; two mild, and two moderate.

Kilincaslan [58] described the benefits of atomoxetine for both social withdrawal and ADHD symptoms in a retrospective open-label observation study of 37 children with comorbid ASD and ID. Eighteen (48.6\%) of the patients were judged responders by $\mathrm{CGI}-\mathrm{I}$, and 16 reached their primary endpoint of CGI-I score 1 or 2 and >_25\% reduction in ADHD-RS-IV score. Neither age nor level of ID correlated with the clinical response to atomoxetine. There was a significant improvement with treatment of $25.8 \%^{* *}$ in ADHD-RS-IV, and ABC parameters of social withdrawal $\left(22 \%^{* * *}\right)$ and hyperactivity $\left(24 \%^{* * *}\right)$. The behavior of 'being uninterested in others' was noted to be improved ( $p$ 0.008) suggesting that atomoxetine may reduce the intensity of certain autism symptoms.

Mazzone and colleagues [59] retrospective open-label observational study investigated the efficacy of atomoxetine across a spectrum of IQ; from 43 to 117 , finding, in contrast to the above papers, a negative correlation between cognitive function and clinical benefit (Pearson's $r=-0.68, p<0.01$ ). Among patients with IQ 70 or less, only one of 17 patients achieved a CGI-I score of 1 or 2 thus 'responder' status; vs 20 of 26 patients with IQ 85 or greater. There was no difference in tolerability.

None of these observational papers calculate statistical power, though they generally had relatively small sample sizes. The sole paper to show a relatively poor impact of atomoxetine had a small sample size of only 17 patients with ID. Fernandez-Jaen's 2010 paper was perhaps the sole reasonably powered paper, with a population of 48 .

\subsection{Evidence for the use of clonidine and guanfacine in ADHD in ID}

Pharmacotherapies for ADHD have gone beyond stimulant medications to include alpha 2 agonists. There are two main second-line medications used in ADHD: clonidine and guanfacine. Clonidine works through alpha $2 \mathrm{~A}, 2 \mathrm{~B}$, and $2 \mathrm{C}$ receptors, whilst guanfacine acts mainly through alpha $2 \mathrm{~A}$ receptors. They mimic norepinephrine actions in the prefrontal cortex through the stimulation of alpha $2 \mathrm{~A}$ receptors [60].

We found one double-blind placebo-controlled trial by Agarwal et al., looking at the efficacy of clonidine in ADHD and ID [61]. This crossover study was conducted on 10 children with hyperkinetic disorder and ID, given successive 4-, 6and $8-\mu \mathrm{g} / \mathrm{kg} / \mathrm{day}$ dosing of clonidine. There were statistically significant improvements in conduct and impulsive-hyperactive symptom scores. In terms of $\mathrm{CGI}-\mathrm{Gl}, 7 / 10$ children on 


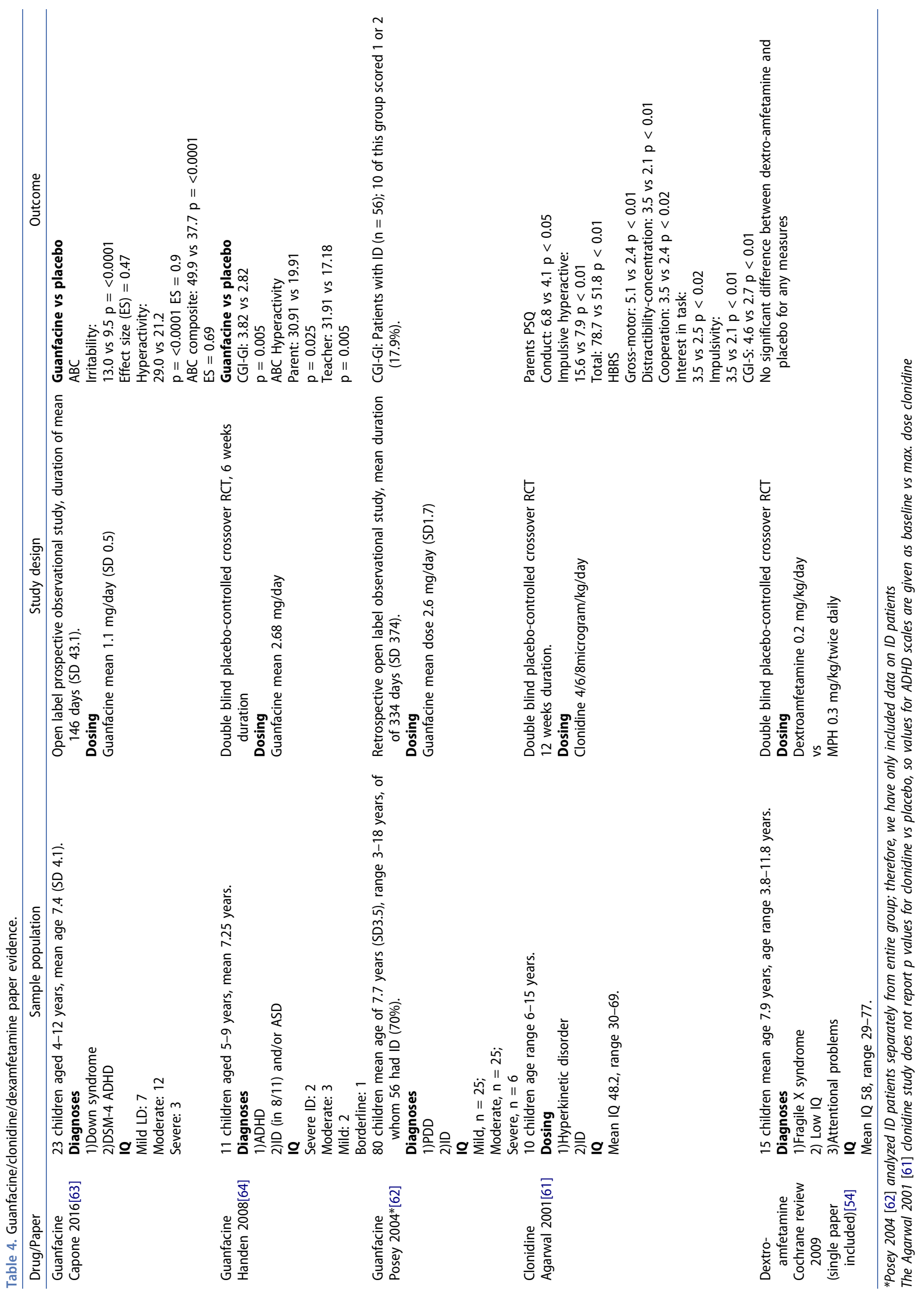


maximal dose were rated as responders, of the remaining three, one achieved remission on a lower dose.

With regards to guanfacine, we found three studies looking at its role in treating ADHD in people with ID. Posey and colleagues [62] conducted a retrospective open-label observational study of guanfacine in 80 children with a mean age of 7.7 years (range 3-18). Fifty-six (70\%) of the patient group had a diagnosis of ID (mental retardation). Guanfacine doses ranged from 0.25 to $9 \mathrm{mg} /$ day. There was a trend $(p=0.06)$ for patients without comorbid ID to respond more frequently with CGI-GI score (37.5\%) following treatment vs those with ID (17.9\%).

Capone and colleagues [63] published an open-label observational prospective study on the efficacy of a mean dose of $1.1 \mathrm{mg} /$ day guanfacine in 23 children aged 4-12, with Down syndrome and ADHD. Statistically significant differences were found in scores of irritability (reducing from 13 to 9.5), hyperactivity (reduced from 29.0 to 21.2 ), and ABC overall composite score (improved from 49.7 to 37.7). They identified a number of specific questions on the $A B C$ scales which were related to disruptive behavior, aggression, inattention, and hyperactivity and combined them to create a novel subscale for each behavior; finding significant improvements in each area.

Handen and colleagues [64] in their double-blind placebocontrolled crossover RCT investigated the role of guanfacine up to $3 \mathrm{mg} /$ day in 11 children aged 5-9 years, with ADHD and ID and/or ASD. They found significant symptomatic improvements in $A B C$ hyperactivity score only, with both parents $\left(36 \%{ }^{*}\right)$ and teachers $\left(56 \%^{* *}\right)$. Three out of five patients who were defined as 'responders' (Handen used a different definition of 'responder' vs the other papers; $a>>50 \%$ decrease in $A B C$ hyperactivity vs placebo) had mild-moderate ID. Of the six non-responders, four had moderate-severe ID.

\subsection{Safety and tolerability}

Studies looking at MPH, amphetamine/dexamfetamine, atomoxetine, clonidine, and guanfacine have reported side effects which are summarized in Table 5. Methylphenidate was most commonly associated with anorexia/weight loss, sleep disturbance, and also minor increases in heart rate, irritability, and anxiety. Amphetamine similarly was associated with irritability \& mood lability.

Guanfacine and clonidine were commonly associated with transient sedation/somnolence. Gl upset, somnolence, and irritability were most commonly reported in atomoxetine. All of the above have been commonly reported in the general population with ADHD [17]. No study found any major difference in type, nature, frequency, and intensity of side effects between the general and ID populations.

\section{Conclusion}

There is evidence to support the use of MPH and atomoxetine in people with ID. This sits well in real-world practice for people with ID. However, there is a need for focused research possible as real-world studies to look at the specific impact of these drugs, particularly, the improvement it brings in issues such as challenging behavior, reduction in other psychotropic medication, and improved quality of life. A lack of awareness of the significant co-morbidity and the erosive impact of ADHD to the individual even to clinical experts working with people with ID has prevented till date suitable mainstream adoption of ADHD diagnosis and treatment.

It is imperative along with fostering further research attempts be made to share the already present evidence especially the over-representation of ADHD in people with ID, the need to treat it proactively, and the role of MPH and atomoxetine. Future research while consolidating on the evidence of the first-line agents specific for people with ID with regard to effectiveness, titration, and dosing could also explore and investigate the role of other agents and combination therapy. Research into impact on social wellbeing and quality of life outcomes could help influence the economic debate.

There could be a developing role in pharmacogenomics and personalized medicine. Identification of particular genetic disorders or people with ID with certain genotypes might enable swifter and better response from ADHD medication while limiting adverse effects. It is hoped that the findings of this paper provide a starting conversation of how to incorporate current good evidence into mainstream practice while evolving patterns of research to enumerate better current gray areas.

\section{Expert opinion}

People with ID should be actively examined for ADHD, and if found should be treated proactively with pharmacological agents irrespective of the level or nature of the ID. While physical and psychological co-morbidity, if present, needs to be weighed against the potential of drug side effects, consideration needs to be also given to the ADHD symptom alleviation and improvements in behavior and quality of life.

With increasing evidence for functional impairment and treatment effectiveness in untreated ADHD in people without ID, there is an improved focus on diagnosis and treatment in people with ID. ADHD medications used in people with ID are similar to those used in the population without ID. The majority of studies found investigated MPH, with few covering atomoxetine, guanfacine, dexamfetamine, and clonidine. Study samples were very small for all studies and focused on children with ID - there were no specific studies looking at ADHD in ID in adults which represented one major weakness. The use of open-label studies and lack of double-blind placebo-controlled trials were other limitations when using results from these studies. Multiple papers published in previous decades, particularly with MPH, mention treatments for ADHD in ID. This review also includes systematic reviews for both methylphenidate \& amphetamine. This gives some confidence to our opinions for the two most commonly prescribed pharmacotherapies for ADHD in ID. 


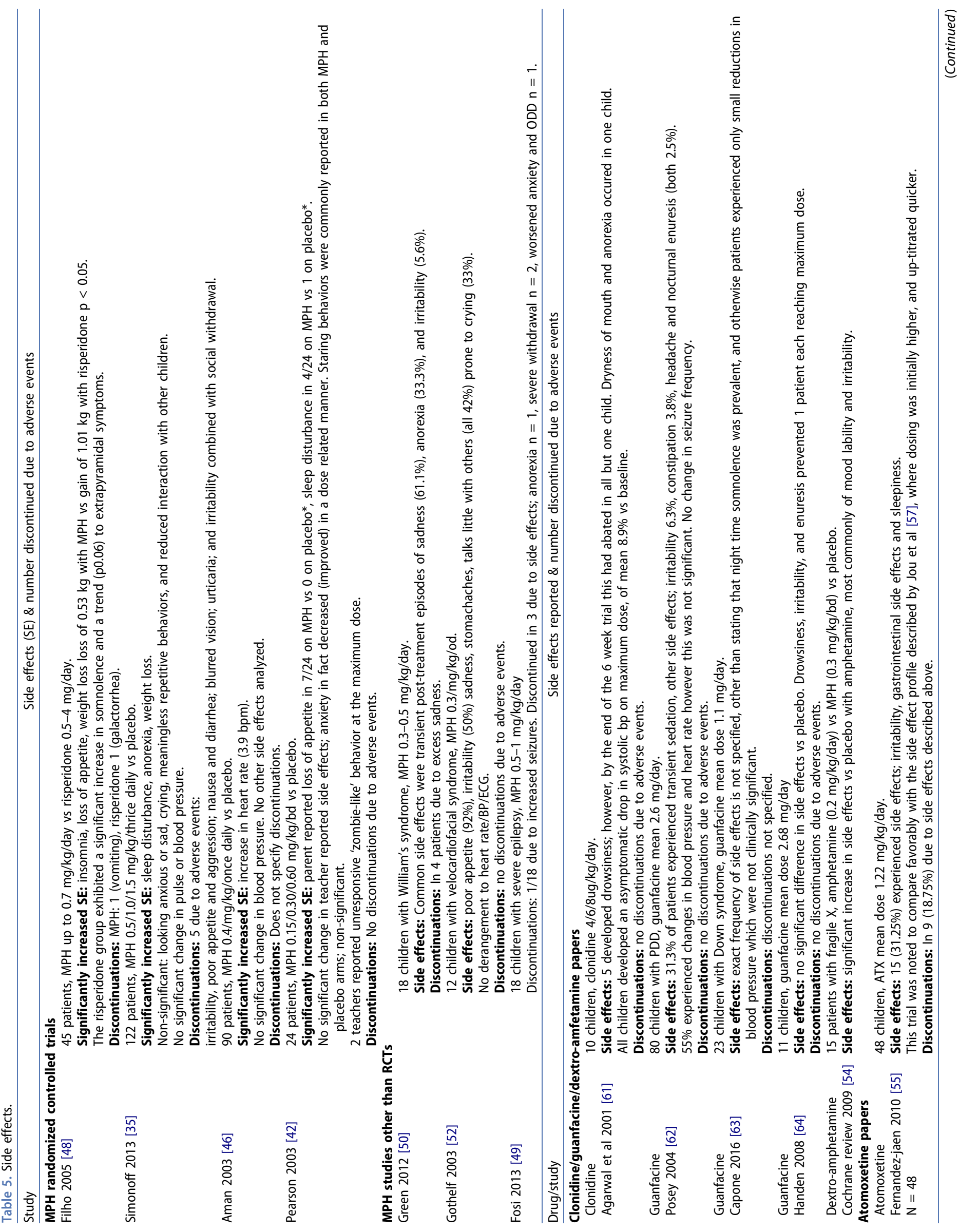




\subsection{Methylphenidate}

Due to the volume, history, and nature of studies, MPH can be regarded as the first-line treatment for ADHD and ID. The evidence base for the use of MPH in people with ID was stronger as compared to other ADHD medications. There were more studies overall, with larger sample sizes and more double-blind placebocontrolled trials. Clear improvement in core symptoms of ADHD in children with ID and ADHD has been demonstrated compared to placebo [34]. A positive association between ADHD severity and $\mathrm{MPH}$ dosage exists, highlighting the importance of titrating the dose up, depending on the symptom improvement. There is a reluctance among psychiatrists working with people with ID to prescribe higher stimulant doses in people with ID; a possible cause for iatrogenic harm, as it can lead to partial or no response to treatment.

No significant differences in dropout rates or treatment discontinuation between children with ID on MPH and placebo have been noted. The associations of initial cognition and behavioral worsening are interesting. This can prompt clinicians and carers/parents to assume that ADHD medications are not tolerated or not effective in a person with ID and $A D H D$, and prevent the full realization of the drug's positive potential. It is worth considering a more gradual titration regime to help build confidence for drug retention, to give the medication its best chance to be effective.

MPH effectiveness, while clear in the ID population in some studies, has been suggested to be lower than that in the general population. However, the above-mentioned bias and confounders could play a role, thus requiring more robust studies to establish this suitably.

In terms of improvements in symptoms, non - ID specific MPH studies have shown an improvement in the core symptoms of ADHD (hyperactivity and inattention), along with other areas, such as improvement in conduct problems and social behavior. There is no evidence to the contrary for ID populations; thus, MPH could be considered for certain aspects of challenging behavior linked to social issues; especially if there are other features of ADHD.

MPH studies also reported overall longitudinal improvements in behavior and cognition, as two independent areas. Some people improved in cognition; without an improvement in behavior; or vice versa. This needs to be taken into consideration when the effectiveness of $\mathrm{MPH}$, in particular, and medication, in general, are assessed in clinical practice - particularly in ID populations.

\subsection{Atomoxetine}

Even though atomoxetine does not have the same volume of studies as $\mathrm{MPH}$, a good argument to use atomoxetine in managing ADHD in people with ID as a first-line medication exists. All studies reviewed identified definite improvement in ADHD symptoms with atomoxetine. All studies save one showed that there was no relationship between treatment outcome and IQ. Improvement was seen in a range of symptoms from core ADHD features to the improvement of comorbid autism-related symptoms reduction in social 
withdrawal. Though limited evidence suggests there is no difference in response to atomoxetine between ID and nonID populations.

Of the particular benefit of atomoxetine is its bioavailability and dosing which lends itself to a single dose a day and provides 24-h cover. This is valuable in people with ID who can be distressed by having to take medication multiple times a day. It could in theory also benefit by providing consistent levels for those who have sporadic behavioral fluctuations during the day, whether atomoxetine is a more suitable ADHD medication for people with ID with challenging behavior needs to be explored using future research.

Commonly reported side effects included irritability, somnolence, and reduced appetite. Twenty to thirty percent of children treated with atomoxetine developed above adverse effects. Side effects were temporary in about half of these children. Clinical experience has shown that side effects can be minimized when atomoxetine is started on doses smaller than what is recommended in BNF. Most studies increased the dose of atomoxetine from $18 \mathrm{mg}$ to $60 \mathrm{mg}$ within 3 weeks which is a faster dose increment compared to what happens in clinical practice. However, very low discontinuation rates were seen in studies where doses were titrated slowly. Available evidence suggests caution in using atomoxetine if there are underlying genetic disorders, particularly those associated with psychiatric symptoms (Fragile $\mathrm{X}$, Tuberous Sclerosis, etc.). An exacerbation of anxiety has been observed.

\subsection{Other medication}

The evidence base for guanfacine, clonidine, and dexamfetamine remains poor for use in people with ID. The only study done in dexamfetamine-based medications showed no clear benefits [38]; however, the study used low doses of amphetamines. Therefore, further studies are needed with a higher dose of amphetamine to assess the efficacy. These cannot presently be advocated as first-line medication for people with ID and ADHD.

\subsection{Other considerations}

Multi-stakeholder feedback particularly from neutral informed sources such as schools is important when evaluating the effectiveness of ADHD medications. Due consideration needs to be given to the presence of other comorbid physical, psychiatric, and neuropsychiatric conditions. Epilepsy is highly prevalent in people with ID. Similarly, a high prevalence rate of ADHD is reported in people with ID. Clinicians are naturally cautious when treating ADHD in people with epilepsy. However, available evidence though limited suggests that drugs such as MPH are safe and can afford over 60\% improvement in ADHD symptoms in people with refractory epilepsy [49]. Larger scale studies are needed to further establish the safety of ADHD medications in people with ID, ADHD, and epilepsy.

Genetic disorders are common among people with ID. Certain genetic syndromes such as Downs' syndrome,
William's syndrome, and Smith Magenis syndrome are strongly associated with ADHD. While the evidence is limited especially for specific disorders, it is likely that treating ADHD with MPH will show a positive response. Importantly the dosing needs to be slow and go low.

Evidence base for the combination of ADHD medication is scarce though MPH and atomoxetine have been recognized to be prescribed together especially in general populations. Combining ADHD medications to further improve target symptoms of ADHD and associated symptoms needs further exploration particularly in people with ID where there is no evidence. Any such attempts in people with ID need to consider the possibility of drug sensitivities, best interest, documented rationale, potential short-term and long-term harm, why monotherapy is not suitable and the impact of out of license prescribing.

\section{Limitations}

This study looked at papers published in the last 20 years and in English only. However, the search in key paper references would identify any important study thus this is not a major bias. Some studies done on people ID and ADHD did not refer to the diagnosis of ADHD in their papers; instead, they described symptoms of ADHD. Such papers could have been missed in the search. However, this confounder has been mitigated by examining references in papers to find out any studies which could be related to the topic inspected. Low-grade evidence papers were included in this review but have been identified and represented clearly in order not to disproportionately affect the final expert opinion.

\section{Funding}

This manuscript has not been funded.

\section{Declaration of interest}

$R$ Shankar has received institutional and research support and personal fees from LivaNova, UCB Pharma, Eisai, Veriton Pharma, Bial, and Desitin. The authors have no other relevant affiliations or financial involvement with any organization or entity with a financial interest in or financial conflict with the subject matter or materials discussed in the manuscript apart from those disclosed.

\section{Reviewer disclosures}

Peer reviewers on this manuscript have no relevant financial or other relationships to disclose.

\section{ORCID}

Rohit Shankar (1D) http://orcid.org/0000-0002-1183-6933

\section{References}

Papers of special note have been highlighted as either of interest $(\cdot)$ or of considerable interest $(\cdot \bullet)$ to readers.

1. Strømme P, Diseth T. Prevalence of psychiatric diagnoses in children with mental retardation: data from a population-based study. Dev Med Child Neurol. 2000;42(4):266-270. 
2. Emerson E. Prevalence of psychiatric disorders in children and adolescents with and without intellectual disability. J Intellectual Disability Res. 2003;47(1):51-58.

3. Barkley RA. Attention-deficit hyperactivity disorder: a handbook for diagnosis and treatment. 3rd ed. New York: Guilford Press; 2006.

4. La Malfa G, Lassi S, Bertelli M, et al. Detecting attention-deficit/ hyperactivity disorder (ADHD) in adults with intellectual disability. Res Dev Disabil. 2008;29(2):158-164.

5. American Psychiatric Association. Diagnostic and statistical manual of mental disorders: DSM-5. 5th ed ed. Arlington (VA): American Psychiatric Association; 2013.

6. Maulik $P$, Mascarenhas $M$, Mathers $C D$, et al. Prevalence of intellectual disability: a meta-analysis of population-based studies. Res Dev Disabil. 2011 March;32(2):419-436. .

7. Hughes-McCormack L, Rydzewska E, Henderson A, et al. Prevalence of mental health conditions and relationship with general health in a whole-country population of people with intellectual disabilities compared with the general population. BJPsych Open. 2017;3 (5):243-248.

8. Cooper S, Smiley E, Morrison J, et al. Mental ill-health in adults with intellectual disabilities: prevalence and associated factors. $\mathrm{Br} J$ Psychiatry. 2007;190(1):27-35.

9. Ettinger A, Ottman R, Lipton R, et al. Attention-deficit/hyperactivity disorder symptoms in adults with self-reported epilepsy: results from a national epidemiologic survey of epilepsy. Epilepsia. 2015;56(2):218-224.

10. Al-Khudairi R, Perera B, Solomou S, et al. Adults with intellectual disability and attention deficit hyperactivity disorder: clinical characteristics and medication profiles. Br J Learn Disabil. 2019;47 (2):145-152.

11. Magon R, Müller U. ADHD with comorbid substance use disorder: review of treatment. Adv Psychiatric Treat. 2012;18(6):436-446.

12. Mannuzza S, Klein R, Moulton J. Lifetime criminality among boys with attention deficit hyperactivity disorder: A prospective followup study into adulthood using official arrest records. Psychiatry Res. 2008;160(3):237-246.

13. Jacob C, Romanos J, Dempfle A, et al. Co-morbidity of adult attention-deficit/hyperactivity disorder with focus on personality traits and related disorders in a tertiary referral centre. Eur Arch Psychiatry Clin Neurosci. 2007;257(6):309-317. .

14. Lichtenstein $P$, Halldner $L$, Zetterqvist J, et al. Medication for attention deficit-hyperactivity disorder and criminality. N Engl J Med. 2012;367(21):2006-2014. .

15. Perera B. Attention Deficit Hyperactivity Disorder in people with Intellectual Disability. Ir J Psychol Med. 2018;35(3):213-219.

16. National Institute for Health and Clinical Excellence. Attention deficit hyperactivity disorder: diagnosis and management. NICE guidelines; London. 2018.

17. Chan E, Fogler J, Hammerness P. Treatment of attention-deficit/ hyperactivity disorder in adolescents. JAMA. 2016;315(18):1997.

18. Cortese S, Adamo N, Del Giovane C, et al. Comparative efficacy and tolerability of medications for attention-deficit hyperactivity disorder in children, adolescents, and adults: a systematic review and network meta-analysis. Lancet Psychiatry. 2018;5(9):727-738.

19. Moher D, Liberati A, Tetzlaff J, et al. Preferred reporting items for systematic reviews and meta-analyses: the PRISMA statement. Int J Surg. 2010;8(5):336-341. .

20. Jou R, Handen B, Hardan A. Psychostimulant treatment of adults with mental retardation and attention-deficit hyperactivity disorder. Australas Psychiatry. 2004;12(4):376-379.

21. Aman MG, Singh N, Stewart A, et al. Psychometric characteristics of the aberrant behavior checklist. Am J Mental Deficiency. 1985;89(5):492-502.

22. Aman MG, Pearson DA. Monitoring and measuring drug effects, Il: behavioral, emotional, and cognitive effects. In: Werry JS, Aman MG, editors. The practitioner's guide to psychoactive drugs for children and adolescents. 2nd ed. Plenum Medical Book Library, New York; 1999. pp 99-164.
23. Conners CK, Sitarenios G, Parker JD, et al. Revision and restandardization of the Conners teacher rating scale (CTRS-R): factor structure, reliability, and criterion validity. J Abnorm Child Psychol. 1998;26(4):279-291.

24. Conners CK, Sitarenios G, Parker JD, et al. The revised Conners' parent rating scale (CPRS-R): factor structure, reliability, and criterion validity. J Abnorm Child Psychol. 1998;26(4):257-268.

25. Swanson JM. School-Based Assessment and Interventions for ADD Students. Irvine, CA: KC Publications; 1992.

26. Ullmann R, Sleator E. Attention deficit disorder children with or without hyperactivity. Clin Pediatr (Phila). 1985;24(10):547-551.

27. Conners CK. Conners' abbreviated symptom questionnaire manual. North Tonawanda, NY: Multi-Health Systems; 1990.

28. Goyette $\mathrm{CH}$, Conners $\mathrm{CK}$, Ulrich RF. Normative data on revised Conners parent and teacher rating scales. J Abnormal Child Psychol. 1978;6(2):221-236.

29. Conners CK. Conners' continuous performance test. Toronto, Ontario, Canada: Multi-Health Systems; 1995.

30. Quay $H$, Peterson D. Manual for the revised behavior problem checklist. Coral Gables FL: University of Miami; 1987.

31. Aman MG. The nisonger CBRF: A child behavior rating form for children with developmental disabilities. Res Dev Disabil. 1996;17(1):41-57.

32. Guy W. ECDEU assessment manual for psychopharmacology. Washington, DC: U.S. DHEW, NIMH; 1976. (NIMH Publication No. 76-338).

33. Tarrant N, Roy M, Deb S, et al. The effectiveness of methylphenidate in the management of attention deficit hyperactivity disorder (ADHD) in people with intellectual disabilities: a systematic review. Res Dev Disabil. 2018;83:217-232.

- A major systematic review, which included a greater breadth of studies to the Sun systematic review/meta-analysis paper

34. Sun C, Tseng P, Wu C, et al. Therapeutic effects of methylphenidate for attention-deficit/hyperactivity disorder in children with borderline intellectual functioning or intellectual disability: A systematic review and meta-analysis. Sci Rep. 2019; 9(1):15908

-. The sole meta-analysis found in our literature search; providing the highest level of evidence regarding the efficacy of MPH in the ID population

35. Simonoff E, Taylor E, Baird G, et al. Randomized controlled double-blind trial of optimal dose methylphenidate in children and adolescents with severe attention deficit hyperactivity disorder and intellectual disability. J Child Psychol Psychiatry. 2013;54(5):527-535. .

-. The biggest and best powered study in our search, and one of the only papers to use a parallel group design, making its findings particularly pertinent to informing work in this area

36. Cohen J. Statistical power analysis for the behavioral sciences. Abingdon: Routledge; 1988.

37. Aman MG, Kern RA, McGhee DE, et al. Fenfluramine and methylphenidate in children with mental retardation and ADHD: clinical and Side Effects. J Am Academy Child Adolesc Psychopharmacol. 1993;32(4):851-859.

38. Hagerman R, Murphy $M$, Wittenberger M. A controlled trial of stimulant medication in children with the fragile $X$ syndrome. Am J Med Genet A. 1988;30(1-2):377-392.

39. MG A, Marks R, Turbott $S$, et al. Clinical effects of methylphenidate and thioridazine in intellectually subaverage children. J Am Acad Child Adolesc Psychiatry. 1991;30(2):246-256.

40. Aman MG, Marks R, Turbott $S$, et al. Methylphenidate and thioridazine in the treatment of intellectually subaverage children. J Am Acad Child Adolesc Psychiatry. 1991;30(5):816-824.

41. Pearson D, Santos C, Casat C, et al. Treatment effects of methylphenidate on cognitive functioning in children with mental retardation and ADHD. J Am Acad Child Adolesc Psychiatry. 2004;43 (6):677-685.

42. Pearson DA, Santos CW, Roache JD, et al. Treatment effects of methylphenidate on behavioral adjustment in children with mental retardation and ADHD. J Am Acad Child Adolesc Psychiatry. 2003Feb1;42(2):209-216. 
- This paper described a curvilinear relationship between MPH and several markers of clinical response; suggesting that even at low doses MPH can provide some benefits

43. Handen B, McAuliffe S, Caro-Martinez L. Learning effects of methylphenidate in children with mental retardation. J Dev Phys Disability. 1996;8(4):335-346.

44. Handen B, Sagady A, McAuliffe-Bellin S. Methylphenidate and play skills in children with intellectual disability and ADHD. J Mental Health Res Intellectual Disabilities. 2009;2(1):1-10.

45. Aman MG, Singh N. Methylphenidate in severely retarded residents and the clinical significance of stereotypic behavior. Appl Res Mental Retardation. 1982;3(4):345-358.

46. Aman M, Buican B, Arnold L. Methylphenidate treatment in children with borderline IQ and mental retardation: analysis of three aggregated studies. J Child Adolesc Psychopharmacol. 2003;13(1):29-40.

47. Pearson D, Lane D, Santos C, et al. Effects of methylphenidate treatment in children with mental retardation and ADHD: individual variation in medication response. J Am Acad Child Adolesc Psychiatry. 2004;43(6): 686-698.

- Paper of particular interest; Pearson and colleagues found that patient's response to MPH in behaviour and cognitive domains can occur independently; i.e. if one only measures a patient's response to MPH using a behavioural measure, you may deem them non-responding - missing their cognitive improvement. Patients may show improvement in one domain, and not another; or in both.

48. Correia Filho A, Bodanese R, Silva T, et al. Comparison of risperidone and methylphenidate for reducing ADHD symptoms in children and adolescents with moderate mental retardation. J Am Acad Child Adolesc Psychiatry. 2005;44(8):748-755.

49. Fosi T, Lax-Pericall $M$, Scott $R$, et al. Methylphenidate treatment of attention deficit hyperactivity disorder in young people with learning disability and difficult-to-treat epilepsy: evidence of clinical benefit. Epilepsia. 2013;54(12):2071-2081.

50. Green T, Avda S, Dotan I, et al. Phenotypic psychiatric characterization of children with Williams syndrome and response of those with ADHD to methylphenidate treatment. Am J Med Genet B Neuropsychiatr Genet. 2011;159B(1):13-20.

51. Green T, Weinberger R, Diamond A, et al. The effect of methylphenidate on prefrontal cognitive functioning, inattention, and hyperactivity in velocardiofacial syndrome. J Child Adolesc Psychopharmacol. 2011;21 (6):589-595.

52. Gothelf D, Gruber R, Presburger G, et al. Methylphenidate treatment for attention-deficit/hyperactivity disorder in children and adolescents with velocardiofacial syndrome. J Clin Psychiatry. 2003;64(10):1163-1169.

53. Faraone SV. The pharmacology of amphetamine and methylphenidate: relevance to the neurobiology of attention-deficit/hyperactivity disorder and other psychiatric comorbidities. Neurosci Biobehav Rev. 2018 1;87:255-270.

54. Castells X, Ramos-Quiroga J, Bosch R, et al. Amphetamines for attention deficit hyperactivity disorder (ADHD) in adults.
Cochrane Database Syst Rev. 2011. DOI:10.1002/14651858. CD007813.pub2

55. Fernández-Jaén A, Fernández-Mayoralas $D$, Calleja Pérez B, et al. Atomoxetine for attention deficit hyperactivity disorder in mental retardation. Pediatr Neurol. 2010;43(5):341-347. .

- The best powered trial investigating atomoxetine in people with ID in the last 20 years

56. Fernández-Jaén $A$, Fernández-Mayoralas $D$, Calleja-Pérez $B$, et al. Efficacy of atomoxetine for the treatment of ADHD symptoms in patients with pervasive developmental disorders. J Atten Disord. 2013;17(6):497-505.

57. Jou R, Handen B, Hardan A. Retrospective assessment of atomoxetine in children and adolescents with pervasive developmental disorders. J Child Adolesc Psychopharmacol. 2005;15 (2):325-330.

58. Kilincaslan A, Mutluer T, Pasabeyoglu B, et al. Effects of atomoxetine in individuals with attention-deficit/hyperactivity disorder and low-functioning autism spectrum disorder. J Child Adolesc Psychopharmacol. 2016;26(9):798-806.

59. Mazzone L, Reale L, Mannino V, et al. Associated with decreased clinical response to atomoxetine in children and adolescents with attention-deficit hyperactivity disorder. CNS Drugs. 2011;25(6): 503-509.

- A large study, which found people with ID responded less well to ADHD medications than those without ID, in this sample group; illustrating the need for more trials in ID patients to understand if medications function differently vs the normal population

60. Ramos B, Stark D, Verduzco L, et al. 2A-adrenoceptor stimulation improves prefrontal cortical regulation of behavior through inhibition of CAMP signaling in aging animals. Learn Memory. 2006;13 (6):770-776.

61. Agarwal V, Sitholey P, Kumar S, et al. Double-blind, placebo-controlled trial of clonidine in hyperactive children with mental retardation. Mental Retardation. 2001;39(4):259-267. .

- The sole double blind placebo controlled RCT conducted in patients given clonidine

62. Posey D, Puntney J, Sasher T, et al. Guanfacine treatment of hyperactivity and inattention in pervasive developmental disorders: a retrospective analysis of 80 cases. J Child Adolesc Psychopharmacol. 2004;14(2):233-241.

- The largest study conducted using guanfacine, it also found that patients with ID respond differently to those without ID; supporting the need for further studies in people with ID

63. Capone G, Brecher L, Bay M. Guanfacine use in children with down syndrome and comorbid attention-deficit hyperactivity disorder (ADHD) with disruptive behaviors. J Child Neurol. 2016;31(8):957964.

64. Handen B, Sahl R, Hardan A. Guanfacine in children with autism and/or intellectual disabilities. J Dev Behav Pediatr. 2008;29(4): 303-308. 


\section{Appendix A1:}

Search terms were as follows:

((('ADHD medication*' OR 'ADHD drug*' OR 'methylphenidate' OR 'concerta $\mathrm{xl}^{\prime}$ OR 'Ritalin' OR 'dexamfetamine' OR 'dexamphetamine' OR 'dextroamphetamine' OR 'Dexedrine' OR 'Adderall' OR 'amfexa' OR 'lisdexamfetamine' OR 'Vyvanse' OR 'elvanse' OR 'Tyvense' OR 'clonidine' OR 'Catapres' OR 'guanfacine' OR 'Tenex' OR 'Atomoxetine' OR 'Strattera')) AND ('ADHD' OR 'ADD' OR 'Attention Deficit Hyperactivity Disorder' OR 'hyperkinetic disorder" OR 'attention deficit disorder")) AND ('Intellectual* disab*' OR 'Intellectual* impair"' OR 'Intellectual' retard*' OR 'Intellectual* handicap" OR 'Intellectual* subnormal ${ }^{* \prime}$ OR 'Intellectual* deficien*' OR 'Learning disab*' OR 'Learning impair*' OR 'Learning retard*' OR 'Learning handicap*' OR 'Learning subnormal*'
OR 'Learning deficien*' OR 'Mental* disab" OR 'Mental* impair*' OR 'Mental* retard"' OR 'Mental* handicap"' OR 'Mental' ${ }^{*}$ subnormal' ${ }^{* \prime}$ OR 'Mental* deficien*' OR 'Developmental* disab"' OR 'Developmental' impair*' OR 'Developmental* retard"' OR 'Developmental* handicap" OR 'Developmental* subnormal*' OR 'Developmental* deficien ${ }^{* \prime}$ OR 'Neurodevelopmental* disab" OR 'Neurodevelopmental* impair"' OR 'Neurodevelopmental* retard"' OR 'Neurodevelopmental* handicap"') We also added MeSH terms:

(1) Exp 'Learning disabilities'

(2) Exp 'Learning disorders'

(3) Exp 'attention deficit disorder'

(4) Exp 'intellectual development disorder'

(5) Exp 'developmental disabilities' 